\title{
Microwave Assisted Synthesis and Evaluation of Cross-Linked Carboxymethylated Sago Starch as Superdisintegrant
}

\author{
Akhilesh V. Singh ${ }^{1}$, Lila K. Nath ${ }^{1}$, Manisha Guha ${ }^{2}$, Rakesh Kumar ${ }^{1}$ \\ ${ }^{1}$ Department of Pharmaceutical Sciences, Dibrugarh University-Dibrugarh, Assam, India; ${ }^{2}$ Grain Science and Technology Depart- \\ ment, CFTRI, Mysore, Karnataka, India. \\ Email: akhileshvikram@gmail.com
}

Received October $20^{\text {th }}, 2010$; revised November $17^{\text {th }}, 2010$; accepted December $13^{\text {th }}, 2010$

\begin{abstract}
The aim of this study was to modify the sago starch and evaluate its efficacy as tablet disintegrant. Cross-linked carboxymethylated sago starch (CMSS) was synthesized using native sago starch (SS) and monochloroacetic acid (MCA) with sodium hydroxide in microwave radiation environment. FT-IR analysis of the sample confirmed the carboxymethylation by showing absorption peak at $1607.2 \mathrm{~cm}^{-1}$. CMSS with degree of substitution (DS) of 0.31 was formed and, it was further evaluated as disintegrant in Ondasetron based tablets. The results revealed that CMSS could be used as disintegrant in tablet formulation in concentration dependant manner.
\end{abstract}

Keywords: Sago Starch, Carboxymethylation, Disintegrant, SEM, FT-IR

\section{Introduction}

Starch is one of the most important and abundant plant polysaccharide next to cellulose and chitin. Starch is found primarily in the seeds, fruits, tubers, and stem pith of plants, most notably corn, wheat, rice, sago, and potatoes. Starch derivatives play vital roles in the promising biopolymers industries. This is because they are cheap, non-toxic, renewable and biocompatible with many other materials for industrial applications. Starches are employed in food, pharmaceutical and allied industries because of its good thickening and gelling properties. Starches can be modified by chemical, physical and enzymatic methods for their tailor made use in different form [1]. They are mainly used as binder, filler, emulsion stabilizer, consistency modifier and disintegrantss. Crosslinked sodium carboxymethyl starch which is also known as sodium starch glycolate is extensively used in fast dissolving tablets to disperse the drugs within short span of time and deliver the active drug in the systemic circulation of the body.

In a number of earlier reported methods, carboxymethylation of starch has been done using strong $\mathrm{NaOH}$ and Mono chloroacetic acis (MCA) in aqueous/organic medium at elevated temperature. It has been shown that when a mixture of starch with sodium hydroxide and monochloroacetic acid is irradiated, the carboxymethyl starch obtained consists of fractions with high levels of carboxymethyl groups and fractions with a predominant content of carbonyl groups [2]. Earlier some workers have modified yam starch and evaluated its efficacy as tablet disintegrant [3]. In our laboratory recently we have synthesized carboxymethylated derivative of moth bean starch by conventional method and evaluated as superdisintegrant [4]. Microwave assisted synthesis is an efficient and novel technique used in polymer synthesis. Microwave-assisted synthesis has attracted huge interest in recent years among researchers due to its rapid transfer of energy in the bulk of the reaction, as well as short reaction time.Compared with the conventional approach a microwave-assisted reaction has advantages of energy saving, high conversion, and rapidity $[5,6]$.

The sago palm (Metroxylon sagu Rottb.) is grown well in the tropical rain forests of Southeast Asia. This palm contains nearly $20-45 \%$ starch on dry weight basis in its trunk and it is one of the potential underutilized palms [7].

This study was designed to synthesize the crosslinked carboxymethyl derivative of sago starch, and evaluate its efficacy as disintegrant in pharmaceutical formulation. Ondasetron was chosen as model drug. 


\section{Material and Methods}

\subsection{Materials}

Sodium starch glycolate and $\mathrm{POCl}_{3}$ was procured from Lobachemie, India. Ondasetron $\mathrm{HCl}$ was kindly donated by Comed Pharmaceuticals Limited, Baddi, India. Monochloro acetic acid (CDH, India) and Sodium hydroxide (Merck, India) were procured and used without further purification. Sago starch was procured from local market of Chennai, Tamilnadu, India. All other chemicals received were of AR grade and used without further purification.

\subsection{Methods}

\subsubsection{Modification of Sago Starch}

Carboxymethylation of Sago starch (SS) was carried out by following slight modified method described elsewhere [8-10]. In this method Sago starch (4 g), NaOH (3.2 g) and monochloroacetic acid $(4 \mathrm{~g})$ were taken in a beaker, with $20 \mathrm{ml}$ of Isopropyl alcohol and water (50:50) and the contents were subjected to continuous stirring to homogeneity. Subsequent reaction was allowed to proceed at varying temperature (from $25^{\circ} \mathrm{C}$ to $70^{\circ} \mathrm{C}$ and duration of reaction (from 1 to $4 \mathrm{~min}$ ) in the Microwave oven (Model No.CE1111TL, Samsung Electronics, India). The reaction products were precipitated with ethanol and washed alkali free and dried in a vacuum oven at $45^{\circ} \mathrm{C}$ for $8 \mathrm{~h}$. The reaction takes place in following manner:

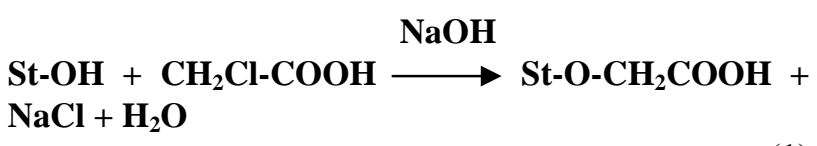

Finally dried powder was further cross-linked with Phosphorous oxychloride $\left(\mathrm{POCl}_{3}\right)$ to get the cross-linked Na-carboxymethylated sago starch (CMSS).

\subsubsection{Degree of Substitution}

The DS of carboxymethylated sago starch (CMSS) was determined by the method reported elsewhere [11].The carboxymethyl groups in the CMSS were first converted to an acid form with acid ( $\mathrm{HCl})$. The acidified starch was then recovered by precipitation with methanol, filtration, washing with methanol, and drying. Then, $0.2 \mathrm{M} \mathrm{NaOH}$ $(20 \mathrm{ml})$ was added to a suspension of accurately weighed CMSS in $30 \mathrm{ml}$ of purified water. The mixture was transferred to a $100-\mathrm{ml}$ volumetric flask and adjusted to the mark with purified water. The solution $(25 \mathrm{ml})$ was transferred to an Erlenmeyer flask and titrated with 0.04 $\mathrm{M} \mathrm{HCl}$ using phenolphthalein as the indicator. The titration was repeated three times, and the average value of $\mathrm{HCl}$ volume was used for the calculations. A blank was also titrated. The DS was calculated using following equations:

$$
\begin{gathered}
\text { Degree of substitution }=\frac{162 \times \mathrm{nCOOH}}{\mathrm{MDS}-58 \times \mathrm{nCOOH}} \\
\mathrm{MDS}=\frac{\left(1-\mathrm{W}_{\text {water }}\right)}{100} \times \mathrm{MS} \\
\mathrm{nCOOH}=\left(\mathrm{V}_{\mathrm{b}}-\mathrm{V}\right) \times \mathrm{C}_{\mathrm{HCl}} \times 4
\end{gathered}
$$

where 162 is the molar mass of $\mathrm{AGU}(\mathrm{g} / \mathrm{mol}) ; \mathrm{nCOOH}$ (mol) is the amount of $\mathrm{COOH}$; MDS (g) is the mass of dry sample; MS ( $\mathrm{g})$ is sample mass: $\mathrm{W}_{\text {water }}(\%)$ is the water content; $\mathrm{V}_{\mathrm{b}}(\mathrm{ml})$ is the volume of $\mathrm{HCl}$ used for the titration of the blank; $\mathrm{V}(\mathrm{ml})$ is the volume of $\mathrm{HCl}$ used for the titration of the sample; $\mathrm{C}_{\mathrm{HCl}}(\mathrm{mol} / \mathrm{L})$ is the $\mathrm{HCl}$ concentration.

\subsubsection{Scanning Electron Microscopy}

Each starch samples were firstly air dried, and then coated with gold. The prepared starch samples were viewed under scanning electron microscope (JEOL, Japan).

\subsubsection{FT-IR Study}

Both native and carboxymethylated starch sample $(5 \mathrm{mg})$ were blended with solid $\mathrm{KBr}$, (Merck, Germany) and about $40 \mathrm{mg}$ blend was used to prepare a pellet (Hydraulic pellet press KP, Mumbai, India).The spectra were scanned from $4000-400 \mathrm{~cm}^{-1}$ in a Perkin Elmer FT-IR spectrometer(Perkin Elmer, USA) under dry air at room temperature.

\subsubsection{Swelling Capacity}

The swelling capacity of the native SS, CMSS and SSG was estimated by slightly modified method of [12]. In this method the tapped volume occupied by $10 \mathrm{gm}$ of the powder $\left(\mathrm{V}_{\mathrm{x}}\right)$, was noted and the powder was dispersed in $85 \mathrm{ml}$ of distilled water and the volume made up to 100 $\mathrm{ml}$ with distilled water. After $24 \mathrm{~h}$ of standing, the volume of the sediment $\left(\mathrm{V}_{\mathrm{v}}\right)$ was measured. The swelling capacity was then computed as the ratio of $\mathrm{V}_{\mathrm{v}} / \mathrm{V}_{\mathrm{x}}$.

\subsubsection{Hydration Capacity}

The slight modified method [13] was used for this study. A $10 \mathrm{gm}$ was placed in each of four $15 \mathrm{ml}$ plastic centrifuge tubes to which $10 \mathrm{ml}$ of distilled water was added and then stoppered. The contents were mixed on a cyclomixer for $2 \mathrm{~min}$. The mixture was allowed to stand for $10 \mathrm{~min}$ and then centrifuged at $1000 \mathrm{rpm}$ for $10 \mathrm{~min}$ on absented centrifuge.

The supernatant was carefully decanted, and the sediment was weighed. The hydration capacity $(\mathrm{Hc})$ was then calculated using the equation:

$$
\mathrm{Hc}=\frac{\text { Sediment weight }}{\text { Dry sample weight }}
$$




\subsubsection{Viscosity Determination}

Viscosity of all the samples were carried out using Brookfield Viscometer (Brookfield Engineering Laboratory, USA) at $25^{\circ} \mathrm{C}$, using spindle no 92 at $6 \mathrm{rpm} \mathrm{h}^{-1}$. The concentration of all the samples were kept at $10 \% \mathrm{w} / \mathrm{v}$.

\subsubsection{Tablet Formulation}

Eight batches of the tablets were prepared using direct compression method. Four batches (F1-F4) contain CMSS; and other four (F5-F8) contains SSG as superdisintegrant in the ratio of 2, 4, 6 and $8 \% \mathrm{w} / \mathrm{w}$ respectively. All ingredients were mixed properly and then powder blend was compressed into tablets using a ten-station tablet compression machine (Shakti Engineering, Ahmedabad, India).

\subsubsection{Evaluation of Tablets}

All the tablets were evaluated for hardness, friability, drug content and percentage weight variation. To evaluate the efficiency of carboxymethylated sago starch as disintegrant in pharmaceutical formulation, the synthesized CMSS was evaluated and compared with established superdisintegrant i.e. Sodium starch glycolate at 2 , 4,6 and $8 \% \mathrm{w} / \mathrm{w}$ concentration as disintegrant in Ondasetron based tablets. The in vitro disintegration study was carried out using USP disintegration apparatus (Tab Machine, Mumbai, India).

\section{Results and Discussions}

Carboxymethylated sago starch with different DS was prepared using MCA and sodium hydroxide in reaction medium of isopropyl alcohol/water. The optimization of carboxymethylation reaction was performed by varying two reaction parameter i.e. reaction temperature and duration of reaction. Each parameter is varied keeping other constant. The influence of these parameters on DS was followed experimentally.

\subsection{Influence of Temperature and Duration of Reaction on Carboxymethylation}

The influence of reaction temperature on DS is shown in Figure 1. The DS of CMSS increases with varying the temperature. The highest DS value (0.31) was obtained at $55^{\circ} \mathrm{C}$ and it decreases further, this could be due to change in its confirmation or, due to degradation. Further all investigations were carried out at $55^{\circ} \mathrm{C}$, since it produced highest DS.

The duration of reaction was varied from 1 to $4 \mathrm{~min}$. The value of DS obtained at different time points are shown in Figure 2. It can be seen that DS value increases with reaction time and further decreases, it might be due to degradation of this polymer. The surface texture of the sago starch is somewhat oval shaped (Figure 3) but after

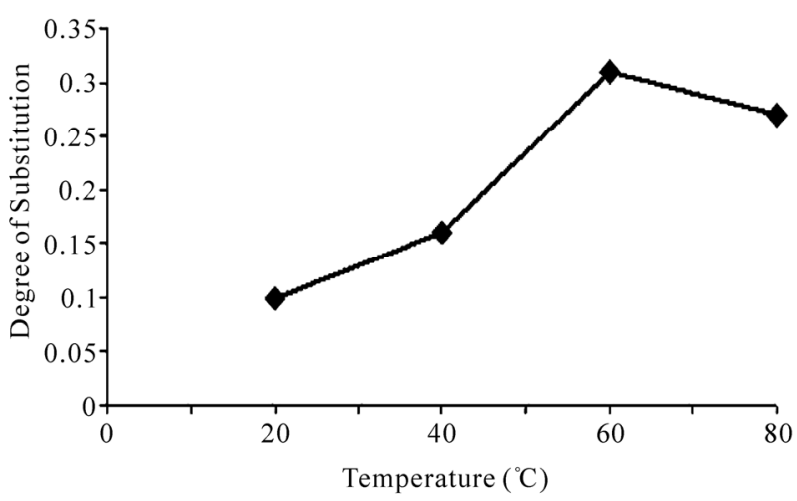

Figure 1. Influence of reaction temperature on DS.

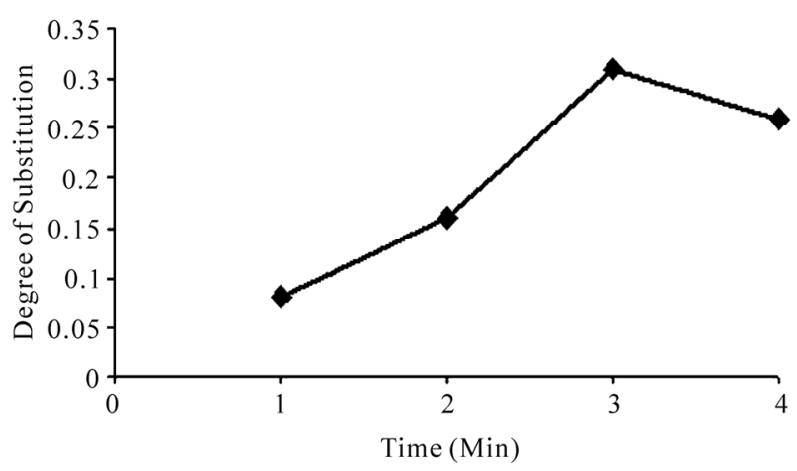

Figure 2. Influence of duration of reaction on DS.

cross-linking the surface texture has been somewhat disoriented that can be seen in Figure 4.

\subsection{Physicochemical Character}

The addition of carboxyl group is indicated by presence of an absorption peak band at 1607.2 in the FT-IR spectrum of CMSS which is not present in native sago starch (shown in Figure 5).The swelling power of the starches is presented in Table 1. The decreasing order of the swelling power was SSG $\approx$ CMSS $>$ SS. The Swelling power of the starches was due to the amylopectin portion and concentration in the starch granules. Water penetration into the starch granules may be increased due to hydrophilic nature of carboxymethyl group, which resulted into swelling of the starch granules, and dissolution in water. Carboxymethylation decreases the amylose content in starch by destruction of helical structure of amylose. Similarly comparative hydration capacity is shown in Table 1, SSG had high hydration capacity as compared to CMSS and SS. This may be due to different DS value of carboxymethylation and amylose/amylopectin ratio and arrangement in starch. The hydration value of CMSS and SSG is more as compared to SS; it may be due to addition of negatively charged carboxymethyl group as well as alkalinization of starch [14]. 


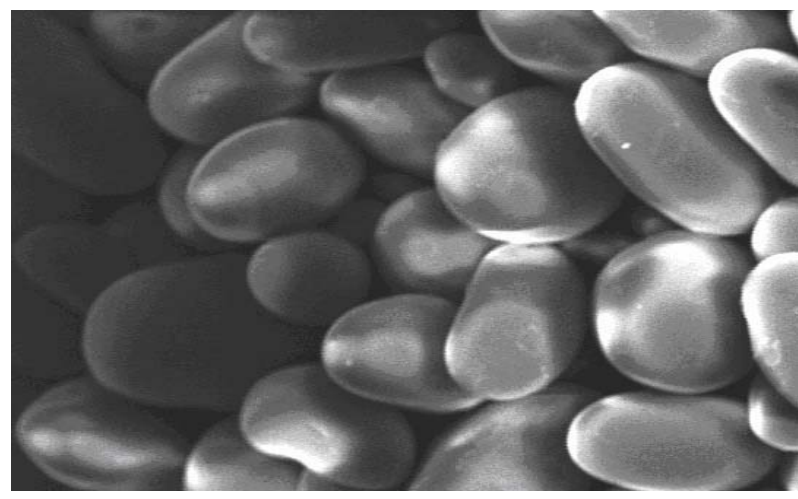

Figure 3. Scanning electron micrograph of native sago starch.

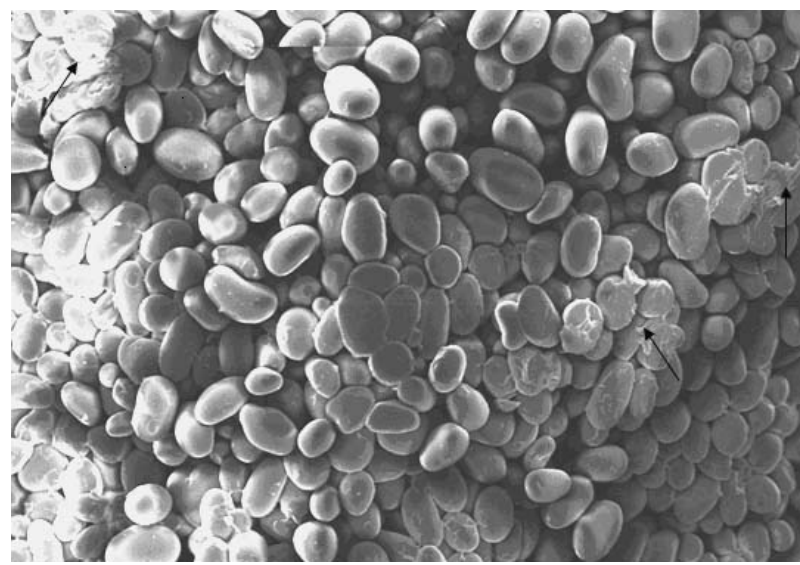

Figure 4. Scanning electron micrograph of carboxymethylated sago starch.

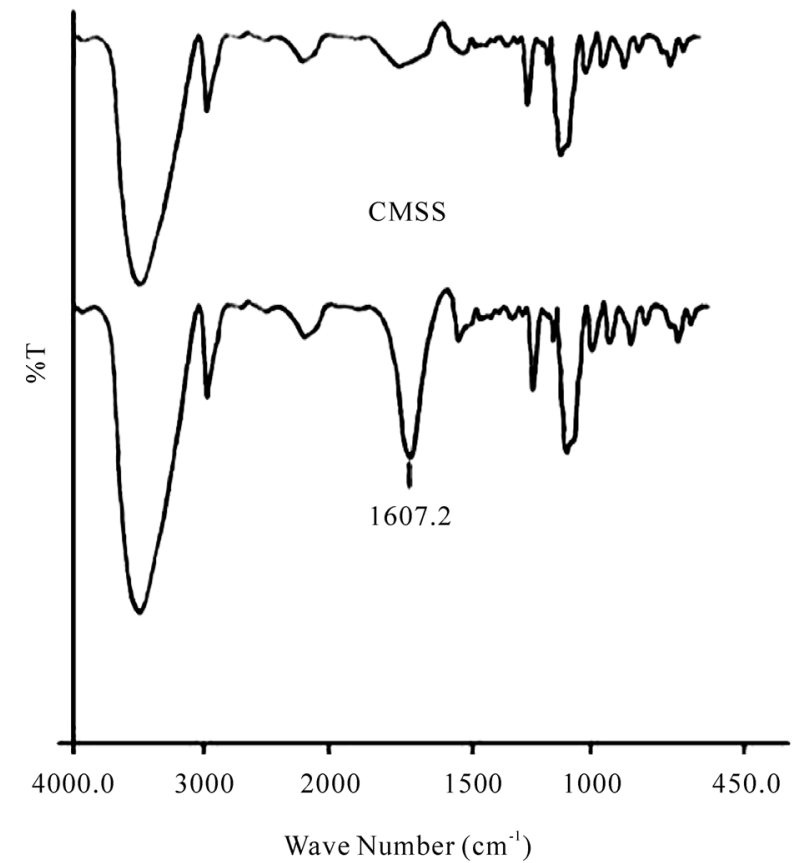

Figure 5. FT-IR spectra of native and modified sago starch.

\subsection{Tablet Evaluation}

All the prepared tablets were evaluated for physical characterization and data shown in Table 2. The results were found within the official limits. Tablets containing different concentration of CMSS and SSG were evaluated for disintegrant property (shown in Figure 6). Carboxymethylation of starch increases its cold-water hydrophilicity due to addition of negatively charged functional group $\left(\mathrm{CH}_{2} \mathrm{COO}^{-}\right)$in the parent chain of native starch. The less concentration of CMSS possesses insufficient swelling power to break the tablets. The tablets containing higher conc. $(6 \% \mathrm{w} / \mathrm{w})$ CMSS showed nearly comparable disintegration time as shown by SSG based tablets. At higher conc. $(8 \% \mathrm{w} / \mathrm{w})$ the disintegration time of both the tablets, mainly SSG based was decreased that may be due to formation of viscous gel mass which impede the penetration of water in to the tablets and retarded the disintegration power. The use of CMSS as a tablet disintegrant in this study seemed to have the optimum concentration at $8 \% \mathrm{w} / \mathrm{w}$.

Table 1. Comparative swelling, hydration and viscosity behavior of all starches.

\begin{tabular}{cccc}
\hline Starch Type & $\begin{array}{c}\text { Swelling } \\
\text { capacity }\end{array}$ & $\begin{array}{c}\text { Hydration } \\
\text { capacity }\end{array}$ & $\begin{array}{c}\text { Viscosity } \\
\text { (cps) }\end{array}$ \\
\hline Sago Starch & $1.6 \pm 0.10$ & $0.68 \pm 0.15$ & 61343 \\
CMSS & $4.0 \pm 0.21$ & $2.2 \pm 0.10$ & 74012 \\
SSG & $4.2 \pm 0.25$ & $2.4 \pm 0.25$ & 75643 \\
\hline
\end{tabular}

All the values are represented as Mean $\pm \mathrm{SD}$; and $\mathrm{n}=3$.

Table 2. Physical Evaluation of tablets.

$\begin{array}{ccccc}\text { Batch } & \begin{array}{c}\text { Hardness } \\ \mathbf{( k g / \mathbf { c m } ^ { 2 } )}\end{array} & \begin{array}{c}\text { Friability } \\ \mathbf{( \% )}\end{array} & \begin{array}{c}\text { Drug content } \\ \mathbf{( \% )}\end{array} & \begin{array}{c}\text { \% Weight } \\ \text { deviation }\end{array} \\ \text { F1 } & 4.6 \pm 0.25 & 0.35 \pm 0.26 & 97.35 \pm 0.35 & 1.3 \pm 0.18 \\ \text { F2 } & 4.7 \pm 0.37 & 0.33 \pm 0.15 & 98.26 \pm 0.20 & 1.0 \pm 0.28 \\ \text { F3 } & 4.3 \pm 0.26 & 0.44 \pm 0.21 & 99.13 \pm 0.21 & 2.5 \pm 0.20 \\ \text { F4 } & 5.2 \pm 0.31 & 0.53 \pm 0.40 & 98.33 \pm 0.26 & 2.7 \pm 0.15 \\ \text { F5 } & 4.9 \pm 0.25 & 0.34 \pm 0.35 & 99.43 \pm 0.23 & 2.1 \pm 0.35 \\ \text { F6 } & 5.0 \pm 0.22 & 0.22 \pm 0.25 & 97.32 \pm 0.20 & 2.4 \pm 0.14 \\ \text { F7 } & 5.2 \pm 0.30 & 0.39 \pm 0.16 & 98.48 \pm 0.30 & 2.9 \pm 0.20 \\ \text { F8 } & 5.1 \pm 0.10 & 0.36 \pm 0.24 & 97.98 \pm 0.34 & 2.1 \pm 0.12\end{array}$

All the values are represented as Mean $\pm \mathrm{SD}$; and $\mathrm{n}=3$. 


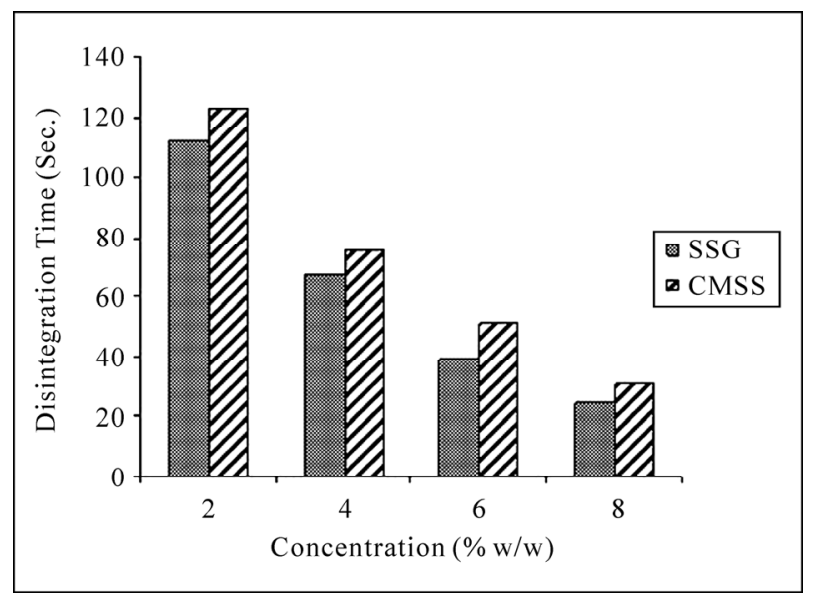

Figure 6. Comparative disintegration behavior in ondasetron based tablets.

\section{Conclusion}

CMSS was synthesized in microwave radiation environment with DS value of 0.31 using $\mathrm{MCA}$ and $\mathrm{NaOH}$ in IPA/ $\mathrm{H}_{2} \mathrm{O}$ solvent medium. The physicochemical values are comparable to official superdisintegrant i.e. SSG, but much higher than native sago starch. CMSS could be used as a potential disintegrant in tablet dosage form at higher concentration $(8 \% \mathrm{w} / \mathrm{w})$.

\section{Acknowledgement}

The authors are thankful to Prof. Harkesh B Singh, Department of Chemistry, IIT-Bomaby for carrying out FT-IR of the samples, and also to IIT-Guwahati for helping in SEM characterization.

\section{REFERENCES}

[1] O. B. Wurzburg, "Modified Starches: Properties and Uses," CRC-Press, Florida, 1984, pp. 4-15.

[2] O. S. Kittipongpatana, J. Sirithunyalug and R. Laenger, "Preparation and Physicochemical Properties of Sodium Carboxymethyl Mungbean Starches," Carbohydrate Polymer, Vol. 63, No. 1, 2006, pp. 105-112. doi:10.1016/j.carbpol.2005.08.024

[3] N. Nattapulwat, N. Purkkao and O. Suwihaayapan, "Preparation and Application of Carboxymethyl Yam (Dioscorea Esculenta) Starch," AAPS PharmSciTechnology, Vol. 10, No. 1, 2009, pp. 193-198. doi:10.1208/s12249-009-9194-5
[4] A. V. Singh, L. K. Nath, R. D. Pandey and A. Das, "Synthesis and Application of Moth Bean Starch as Superdisintegrant in Pharmaceutical Formulation," Journal of Polymer Materials, Vol. 27, No. 2, 2010, pp. 173-177.

[5] V. Singh and A. Tiwari, "Microwave Accelerated Methylation of Starch," Carbohydrate Research, Vol. 343, No. 1, 2008, pp. 151-154. doi:10.1016/j.carres.2007.09.006

[6] A. N. Jyothia, K. N. Rajasekharanb, S. N. Moorthy and J, Sreekumara, "Microwave Assisted Synthesis and Characterization of Succinate Derivative of Cassava (Manihot Esculenta) Starch," Starch/Starke, Vol. 57, No. 11, 2005, pp. 556-563. doi:10.1002/star.200500429

[7] Z. A. Noor Fadzlina, A. A. Karim and T. T. Teng, "Physicochemical Property of Carboxymethyl Sago ( Metroxylan Sagu) Starch," Journal of Food Science, Vol. 70, No. 9, 2005, pp. 560-567. doi:10.1111/j.1365-2621.2005.tb08305.x

[8] S. Zeiko, J. J. Katarina and J. Slobodan, "Synthesis of Carboxymethyl Starch," Starch/Starke, Vol. 52, No. 11, 2000, pp. 413-419.

doi:10.1002/1521-379X(200011)52:11<413::AID-STAR 413>3.0.CO;2-B

[9] P. D. Pandya, N. K. Patel and V. K. Sinha, "Synthesis and Characterization of Sodium Salt of Partially Carboxymethylated Starch," International Journal of Polymeric Materials, Vol. 51, No. 12, 2002, pp. 1081-1085. doi: $10.1080 / 714975698$

[10] S. Kamel and K. Jahangir, "Optimization of Carboxymethylation of Starch in Organic Solvents," International Journal of Polymeric Materials, Vol. 56, No. 5, 2007, pp. 511-519. doi:10.1080/00914030600945770

[11] Z. Stojanovic, K. Jeramics, S. Jovanovic and D. M. Lechner, "A Comparison of Some methods for the Determination of the Degree of Substitution of Carboxymethyl starch," Starch/Starke, Vol. 51, No. 1, 2005, pp. 79-83. doi:10.1002/star.200400342

[12] A. O. Okhamafe, A. Igboechi and T. O. Obasaki, "Celluloses Extracted from Groundnut Shell and Rice Husk. 1: Preliminary Physicochemical Characterization," Pharmacy World Journal, Vol. 8, No. 4, 1991, pp. 121-123.

[13] S. S. Komblum and S. B. Stoopak, "A New Tablet Disintegrant: Crosslinked Polyvinylpyrrolidine," Journal of Pharmaceutical Sciences, Vol. 62, No. 1, 1973, pp. 43-49. doi:10.1002/ jps.2600620107

[14] M. I. Khalil, A. Hashem and A. Hebesish, "A Carboxymethylation of Maize Starch," Starch/Starke, Vol. 42, No. 2, 1990, pp. 60-63. doi:10.1002/star.19900420209 